\title{
DETERMINAÇÃO DAS COMPOSIÇÕES FÍSICO-QUÍMICAS DE CACHAÇAS DÓ SUL DE MINAS GERAIS E DE SUAS MISTURAS
}

\author{
Determination of the physical-chemical composition of homemade cachaças produced in the \\ South of Minas Gerais and their mixtures
}

\author{
Fernando José Vilela', Maria das Graças Cardoso², José Masson³, Jeancarlo Pereira dos Anjos ${ }^{4}$
}

\begin{abstract}
RESUMO
Este trabalho teve por objetivo a determinação da composição físico-química de cachaças artesanais produzidas no sul do Estado de Minas Gerais e suas misturas. Foram analisados os teores de etanol, acidez volátil, aldeídos, cobre, ésteres, álcoois superiores totais e metanol, além dos álcoois propanol-1, isobutanol e 3-metil-butanol-1. Os resultados apresentam o perfil peculiar desta bebida, que apresentou teores satisfatórios de álcoois superiores, ésteres e aldeídos. O teor de cobre apresenta-se como preocupante já que algumas amostras excederam o limite de $5 \mathrm{mg} . \mathrm{L}^{-1}$. A produção de misturas foi estudada e esta apresenta-se como uma alternativa viável ao produtor e cooperativas.
\end{abstract}

Termos para indexação: Cachaça, controle de qualidade, cromatografia.

\begin{abstract}
The present study sought the physical-chemical composition of homemade cachaças produced in the south of the state Minas Gerais and of mixtures of the same cachaça samples. The ethanol, aldehyde, copper, higher alcohol, volatile acid and methanol concentrations were determined, in addition to the individual propanol, 2-methyl-1-propanol and 3-methyl-1-butanol concentrations. The results demonstrated the characteristic profile of this beverage, which presented satisfactory concentrations of higher alcohols, esters, and aldehydes. The copper concentrations of some samples exceeded the limit of $5 \mathrm{mg}$. $\mathrm{L}^{-1}$. The mixtures produced from some of the cachaça samples presented a viable alternative for the producers and cooperatives because the concentrations of the components were more adequate for exportation.
\end{abstract}

Index terms: Cachaça, quality control, chromatography.

\section{(Recebido em 4 de outubro de 2005 e aprovado em 3 de outubro de 2006}

\section{INTRODUÇÃo}

A Instrução Normativa número 13, de 29 de junho de 2005, define como cachaça a bebida com graduação alcoólica de trinta e oito a quarenta e oito por cento em volume, a vinte graus Celsius, obtida de destilado alcoólico simples ou pela destilação do mosto fermentado de canade-açúcar, podendo ser adicionada de açúcares até seis gramas por litro (BRASIL, 2005a). A globalização tem influenciado consideravelmente nos hábitos de consumo de pessoas do mundo todo. Isto faz com que se necessite de um maior controle e conhecimento de produtos comercializados no mercado interno e externo, devendo se efetuar técnicas de padronização, especificação e certificação (FERNANDES et al., 2005). A cachaça é a bebida destilada mais consumida no Brasil. Estima-se um consumo de dois bilhões de litros anualmente, envolvendo um capital de dois bilhões de dólares, distribuídos em todas as classes sociais (DRINKS..., 1994; IMPACT..., 1996).

A produção de cachaça de modo artesanal resulta em algumas peculiaridades no produto final. Trabalhos de Faria (1989) relatam que o cobre usado nos destiladores catalisa algumas reações e retira alguns odores desagradáveis encontrados em cachaças produzidas em alambiques de outros materiais, como o aço inoxidável e outros. Em consequiência do uso destes destiladores, um dos maiores problemas encontrados nas cachaças artesanais é o excesso deste metal. Vários produtores utilizam diferentes materiais para retirar o excesso de cobre. Dentre os mais comuns encontra-se o carvão ativado e as resinas de troca iônica. Dados de Lima et al. (2006) mostraram que as resinas se apresentam como a melhor opção para retirar o excesso de cobre, influenciando pouco na concentração dos congêneres.

\footnotetext{
Graduado em Química - Departamento de Química/DQI - Universidade Federal de Lavras/UFLA - Cx. P. 3037 - $37200-000$ - Lavras, MG nandodemolay@yahoo.com.br - Bolsista de Iniciação Cientifica pelo CNPq.

²Doutora em Química Orgânica, Professor Associado - Departamento de Química/DQI - Universidade Federal de Lavras/UFLA - Cx. P. 3037 - $37200-000$ Lavras, MG - mcardoso@ufla.br

${ }^{3}$ Mestre em Ciência dos Alimentos - Centro Federal de Educação Tecnológica de Cuiabá - Br 364, Km 329 - $78106-000$ - São Vicente da Serra, MT masson_cefetcuiaba@yahoo.com.br

${ }^{4}$ Graduando em Química - Departamento de Química/DQI - Universidade Federal de Lavras/UFLA - Cx. P. 3037 - $37200-000$ - Lavras, MG jeancarloufla@yahoo.com.br - Bolsista de Iniciação FAPEMIG.
} 
Na cachaça são encontradas inúmeras substâncias. Algumas apresentam características indesejáveis, dentre essas estão o formaldeído e o carbamato de etila e o furfural, potencialmente carcinogênicos. Dentre os narcóticos estão o formaldeido e o benzaldeído. Estes compostos fazem parte da fração orgânica da bebida e sua produção pode ser influenciada pela cana-de-açúcar, pela fermentação, pelo método de destilação e pelo envelhecimento (CARDOSO, 2006; SIEBALD et al., 2002).

Os álcoois superiores com 3 a 5 átomos de carbono são freqüentemente encontrados em bebidas destiladas. Estes, conhecidos com o óleo fúsel, geralmente apresentam um odor característico de flores, e, juntamente com os ésteres, são responsáveis pelo "flavour" da cachaça. Os principais álcoois superiores encontrados em cachaças são os álcoois isoamílico (2-metilbutanol-1), amilico (pentanol), isobutílico (2-metilpropanol-1) e propílico (propanol) (PIGGOTT et al., 1989). Trabalhos de Sousa et al. (1978) descrevem que grandes quantidades de óleo fúsel diminuem o valor comercial e a qualidade das cachaças e que o teor de álcoois superiores normalmente deve acompanhar proporcionalmente os ésteres em uma cachaça de boa qualidade.

Segundo Giudici et al. (1990), a produção de álcoois superiores parece ser uma característica das leveduras em geral, e as quantidades produzidas variam com as condições de fermentação, com o gênero, espécie, e provavelmente com a cepa utilizada. Estes analisaram a capacidade de produção de álcoois superiores em 100 cepas de Saccharomyces cerevisae e constataram que a produção de álcool superior é uma característica individual da cepa. Estes resultados foram confirmados por Oliveira (2001). Diante do exposto, com o presente trabalho objetivou-se determinar as composições físico-química de cachaças produzidas artesanalmente no sul de Minas Gerais e de suas misturas.

\section{MATERIAL E MÉTODOS}

Foram coletadas vinte e uma amostras de cachaças aleatoriamente em diferentes regiões do Sul de Minas Gerais, Brasil. Realizaram-se as análises de grau alcoólico, acidez volátil, cobre, metanol, álcool superior, ésteres e aldeídos segundo metodologia de Brasil (2005b). Todas as análises foram realizadas em triplicata.

Os álcoois superiores propanol, butanol, 2metilpropanol-1 e 3-metilpentanol-1 foram identificados e quantificados por cromatografia gasosa no cromatógrafo Shimadzu CG - 17A, injeção manual, detector de ionização de chama (FID), coluna DB-WAX, fase estacionária polietileno glicol ( $30 \mathrm{~m} \times 0,25 \mathrm{~mm} \times 0,25 \mathrm{~mm}$ ). A temperatura foi de $150{ }^{\circ} \mathrm{C}$ para o injetor e o detector. O programa de temperatura utilizado foi de $60{ }^{\circ} \mathrm{C}(2,5 \mathrm{~min})$, subindo $2{ }^{\circ} \mathrm{C}$ $\mathrm{min}^{-1}$ até $80^{\circ} \mathrm{C}(2,0 \mathrm{~min})$. $\mathrm{O}$ volume de amostra injetado foi de 1,0 mL; a taxa de "split" foi de 1:30; os gases utilizados foram: para arraste o nitrogênio e para a formação de chama, o hidrogênio e ar sintético; todos com pressão de $3 \mathrm{kgf}$. $\mathrm{cm}^{-2}$; o fluxo de coluna foi de $1,38 \mathrm{~mL} \mathrm{~min}^{-1}$, a pressão 14,9 psi e a velocidade linear foi de $32,73 \mathrm{~cm} \mathrm{~s}^{-1}$.

Os padrões utilizados foram das marcas Merck para o propanol, butanol, 3-metilbutanol-1 e pentanol e Supelco para o 2-metilpropanol-1. Construíram-se curvas analíticas plotando-se a área do cromatograma versus a concentração da solução. Foi preparada uma mistura com as cachaças que apresentavam um menor teor de cobre, visando um produto que atendesse à legislação vigente.

\section{RESULTADOS E DISCUSSÃO}

\section{Perfil físico-químico das cachaças analisadas}

Os resultados das análises físico-químicas mostraram a diversidade das cachaças sul-mineiras, representando o espaço amostral amplo. Os resultados estão apresentados na Tabela 1.

Com relação à concentração de ésteres, percebe-se que as cachaças analisadas não apresentam quantidades acima do limite máximo permitido pela legislação, que é de $150 \mathrm{mg} .100 \mathrm{~mL}^{-1}$ de álcool anidro. Este resultado era esperado, já que todas as cachaças utilizadas eram recémdestiladas, e a concentração deste composto aumenta durante o envelhecimento.

A concentração de aldeídos na maioria das amostras não apresenta-se em excesso, porém, quatro amostras estão em situação preocupante. Estas são as amostras 20 e 15 (acima do teor máximo permitido) e as amostras 16 e 5 (com concentração relativamente alta). $\mathrm{O}$ valor máximo permitido pela legislação é $30 \mathrm{mg} .100 \mathrm{~mL}^{-1}$ de álcool anidro. $\mathrm{O}$ aldeído é um composto que diminui a qualidade da cachaça e, quando ingerido, interfere no sistema nervoso central, portanto é importante quantificálo, sendo que sua concentração deverá ser o mínimo possível.

Com relação aos álcoois superiores, pode-se perceber que nenhuma amostra tem concentração superior ao valor máximo permitido. ( $360 \mathrm{mg} / 100 \mathrm{~mL}$ álcool anidro). A baixa concentração de álcoois superiores pode estar relacionada com os cuidados no corte da cana, assim como no tempo de espera para a moagem e fermentação. 


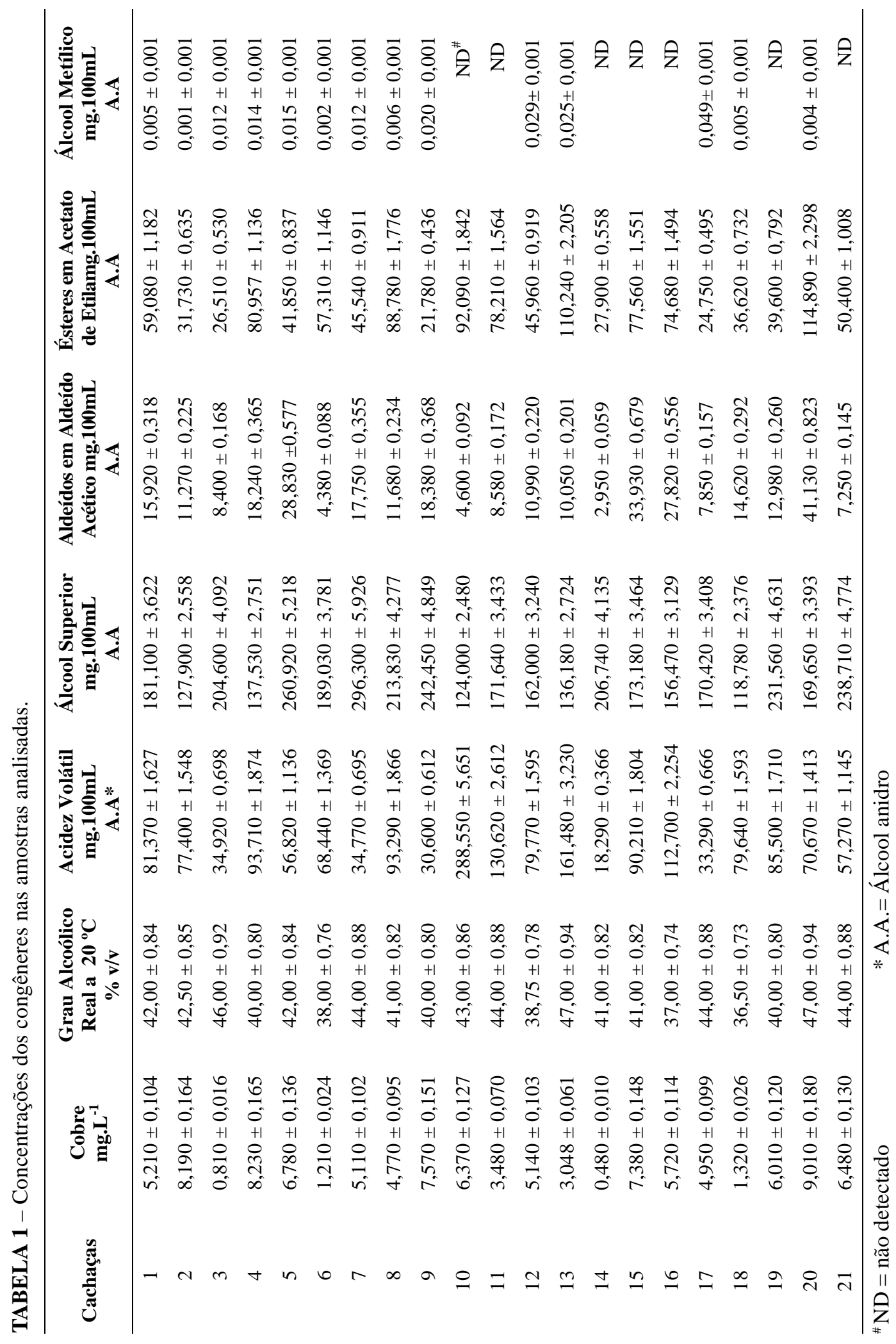

Ciênc. agrotec., Lavras, v. 31, n. 4, p. 1089-1094, jul./ago., 2007 
A análise do teor de acidez volátil mostrou que somente duas amostras apresentaram teor acima do permitido, que é de $150 \mathrm{mg} .100 \mathrm{~mL}^{-1}$ de álcool anidro, sendo que a amostra 10 apresentou um teor muito elevado. Uma alta concentração de acidez volátil pode ser reflexo de uma má fermentação ou má higienização do alambique.

A concentração de metanol apresentou valores bastante baixos ou quantidades não detectadas para todas as amostras. Este é um bom sinal, pois, como já foi mencionado, este álcool é extremamente indesejável. A presença do metanol na bebida pode estar ligada à má filtragem do caldo, o que possibilita a presença de bagacilhos no processo fermentativo, que podem ser degradados a metanol.

Quanto ao grau alcoólico, somente duas cachaças apresentaram-se com teor abaixo do permitido, estando todas as outras dentro dos padrões. Os valores permitidos pela legislação são de 38 a $48 \%$ v/v de etanol.

Os valores das concentrações de cobre são preocupantes. Diante das análises, constatou-se que quatorze amostras estão acima do limite permitido, três estão em condições limites e somente duas estão abaixo do índice ideal para a exportação. Este metal é proveniente de uma má assepsia do alambique, pois nos alambiques confeccionados com cobre, há normalmente a formação do azinhavre, carbonato básico de cobre $\left[\mathrm{CuCO}_{3}(\mathrm{OH})_{2}\right]$, que, no momento da destilação, é arrastado pelos vapores ácidos e alcoólicos da cachaça.

\section{Preparação de uma mistura das amostras}

Para que se pudesse produzir um produto com composição aceitável, preparou se uma mistura com as cinco amostras que apresentavam menores teores de cobre. Esta mistura deve ser produzida com extremo controle da qualidade físico-química das cachaças utilizadas, e, conforme a concentração de congêneres desejados, deve-se calcular a quantidade de cada amostra utilizada. O resultado de três misturas com diferentes proporções das cinco cachaças com menor teor de cobre está apresentado pelo Gráfico 1.

As misturas produzidas apresentaram concentrações aceitáveis de todos os componentes, viabilizando assim a sua comercialização. As proporções estão apresentadas abaixo: Mistura1: $20 \%$ amostra $13 ; 25 \%$ amostra $14 ; 25 \%$ amostra $3 ; 15 \%$ amostra $6 ; 15 \%$ amostra 18

Mistura2: $30 \%$ amostra 18; $30 \%$ amostra 3; $20 \%$ amostra 6; $10 \%$ amostra $14 ; 10 \%$ amostra 13

Mistura3: $30 \%$ amostra 18; 20\% amostra13; 20\% amostra $6 ; 15 \%$ amostra $14 ; 15 \%$ amostra13

\section{Análises cromatográficas}

A análise dos álcoois superiores por cromatografia gasosa foi realizada somente para as cinco cachaças com menor teor de cobre e para a mistura preparada com igual proporção entre elas. Os resultados obtidos estão apresentados no Gráfico 2.

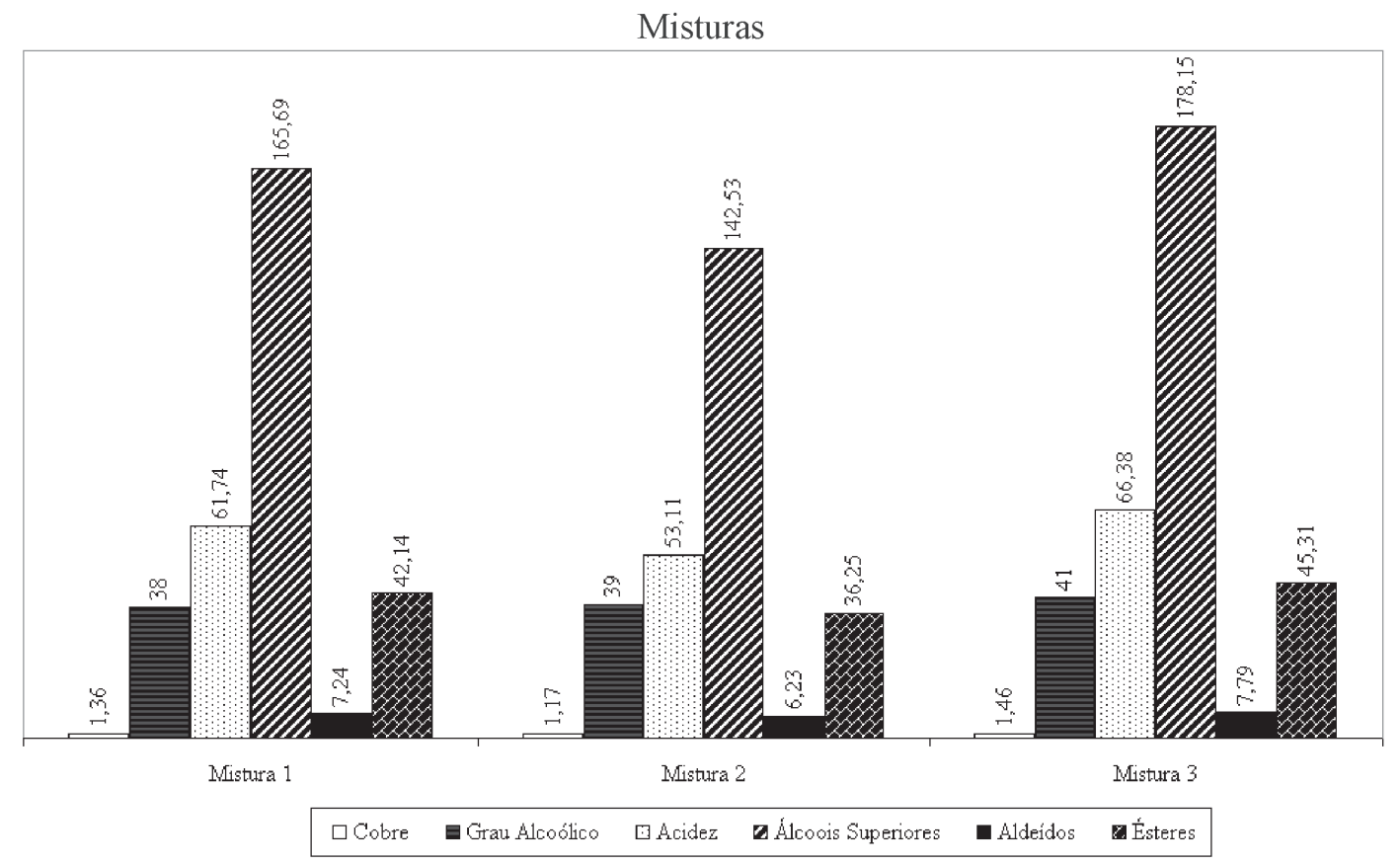

GRÁFICO 1 - Concentração de congêneres das misturas preparadas com diferentes proporções das cinco cachaças de melhor qualidade físico-química. 
Concetração dos alcoois superiores em cachaça

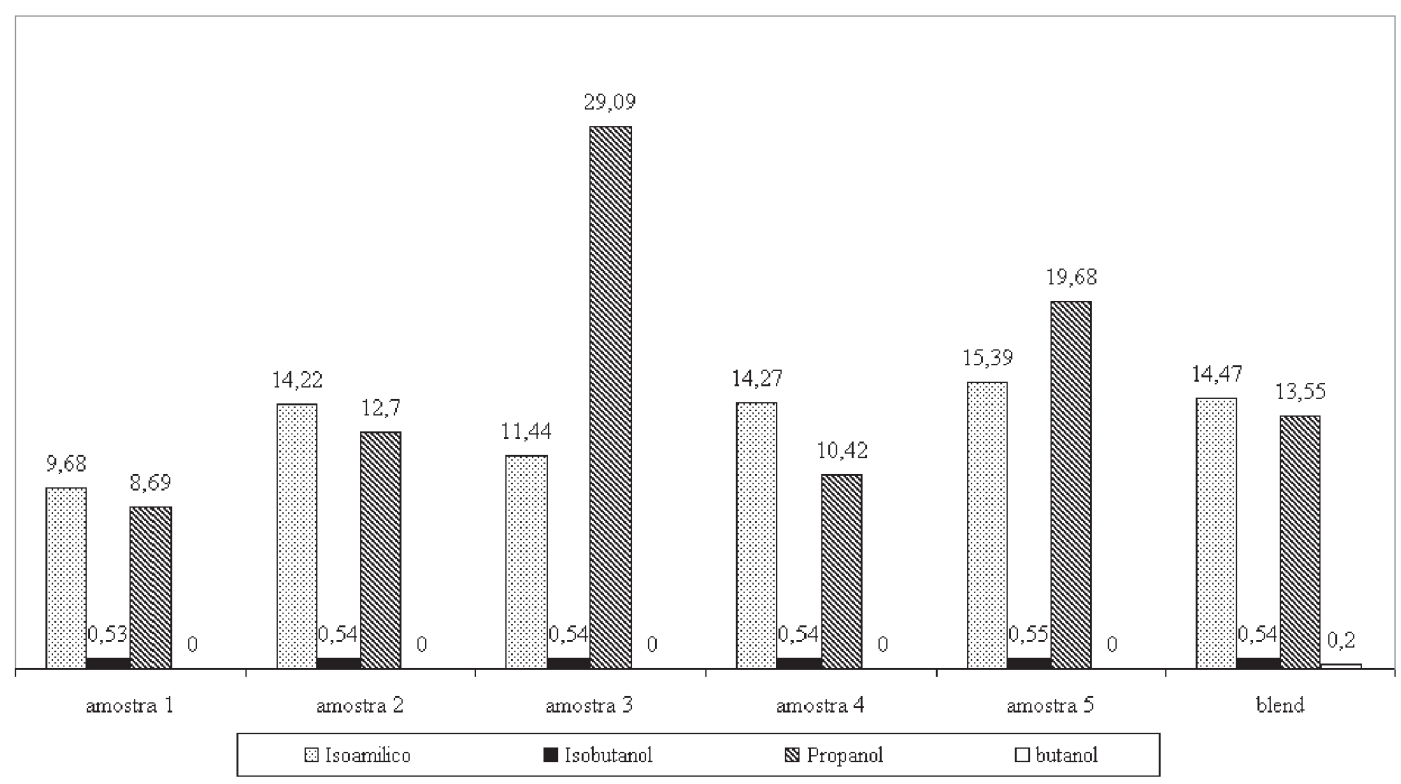

GRÁFICO 2 - Concentrações de álcoois superiores analisados por cromatografia gasosa.

Pela análise dos dados do Gráfico 2, pode-se perceber que as amostras analisadas apresentaram os álcoois propanol-1, isobutanol e 3-metil-butanol-1 (isoamílico). Estes compostos são produzidos durante o processo fermentativo, sendo que suas proporções podem variar conforme a levedura utilizada (GIUDICI et al., 1990). As amostras analisadas apresentaram uma boa proporção entre esses álcoois, sendo que apenas a amostra III apresentou uma elevada concentração de propanol, o que, deprecia a qualidade da bebida. A quantificação do butanol1 na mistura, sendo que este composto não foi quantificado nas amostras individuais, pode ser indício de contaminação na amostragem ou na análise cromatográfica.

\section{CONCLUSÃO}

Com os resultados obtidos pode-se perceber que as cachaças analisadas apresentam boa qualidade físicoquímica, ressaltando-se que se deve dispensar uma atenção especial à concentração de cobre. A produção de uma mistura apresentou-se como uma boa alternativa para atender a demanda externa, desde que seja preparado a partir de cachaças com de boa qualidade. Com o aumento da demanda, este produto tende a apresentar cada vez mais características homogêneas, visando a padronização de um produto de qualidade, facilitando assim a produção de misturas.

\section{AGRADECIMENTOS}

Os autores gostariam de agradecer ao CNPq, FAPEMIG e aos produtores por cederam as amostras.

\section{REFERÊNCIAS BIBLIOGRÁFICAS}

BRASIL. Instrução normativa ${ }^{\circ} 13$, de 29 de junho de 2005. Aprova o regulamento técnico para fixação dos padrões de identidade e qualidade para aguardente de cana e para cachaça. Diário Oficial da União, Brasília, jun. 2005a.

BRASIL. Instrução normativa $\mathrm{n}^{\circ} 24$, de 08 de setembro de 2005. Manual operacional de bebidas e vinagres. Diário Oficial da União, Brasília, set. 2005b.

\section{CARDOSO, M. G. Produção artesanal de aguardente.} Lavras: UFLA, 2006.

DRINKS international. [S.1.], 1994.

FARIA, J. B. A influência do cobre na qualidade das aguardentes de cana (Saccharum officinerum). 1989. Tese (Doutorado) - Faculdade de Ciências Farmacêuticas, Universidade de São Paulo, São Paulo, 1989. 
FERNANDES, A. P.; SANTOS, M. C.; LEMOS, S. G.; FERREIRA, M. M. C.; NOGUEIRA, A. R. A.; NOBREGA, J. A. Pattern recognition apllied to mineral caracterizaton of Brazilian coffes and sugar-cane spirits. Spectrochimica ACTA, Part B, [S.1.], 2005.

GIUDICI, P.; ROMANO, P.; ZAMBONELLE, C. A biometric study of higher Alcohol production in Saccharomyces Serevisae. Canadian Journal of Microbiology, Ottawa, v. 33, n. 2, p. 61-64, Jan. 1990.

IMPACT international. [S.1.: s.n.], 1996.

LIMA, A. de J. B.; CARDOSO, M. G.; GUERREIRO, M. C.; PIMENTEL, F. A. Emprego do carvão ativado para remoção de cobre em cachaça. Química Nova, São Paulo, v. 29, n. 2, p. 247-250, 2006.
OLIVEIRA, E. S. Características fermentativas, formação de compostos voláteis e qualidade da aguardente de cana obtida por linhagens de leveduras isoladas em destilarias artesanais. 2001. 135 f. Tese (Doutorado em Tecnologia de Alimentos) Universidade Estadual de Campinas, Campinas, 2001.

PIGGOTT, J. R.; SHARP, R.; DUNCAN, R. E. B. The sciense and technology of whiskies. New York: Longman, 1989.

SIEBALD, H. G. L.; CANUTO, M. H.; LIMA, G. M.; SILVA, L. B. B. Alguns aspectos toxicológicos da cachaça. Informe Agropecuário, Belo Horizonte, v. 23, n. 217, p. 59-62, 2002.

SOUSA, L. G.; LLISTÓ, A. M. S. M. Alguns componentes do coeficiente não álcool da aguardente de cana: determinação por cromatografia de fase gasosa. Brasil Açucareiro, Rio de Janeiro, n. 3, p. 109, 1978. 